\title{
Importance of considering interoceptive abilities in alexithymia assessment
}

\author{
Alicia Fournier ${ }^{\text {Corresp., } 1,2}$, Olivier Luminet ${ }^{3,4}$, Michael Dambrun $^{5}$, Frédéric Dutheil ${ }^{5,6,7}$, Sonia Pellissier ${ }^{8}$, Laurie \\ Mondillon ${ }^{\text {Corresp. } 5}$ \\ 1 Laboratory Psy-DREPI, Université de Bourgogne, Dijon, France \\ Behaviors, risk and Health, CNRS, MSHE Claude-Nicolas Ledoux, Besançon, France \\ 4 \\ Belgium and Fund for Scientific Research (FRS-FNRS), Brussels, Belgium \\ 5 Laboratoire de Psychologie Sociale et Cognitive (LAPSCO), CNRS UMR 6024, Université Clermont Auvergne, Clermont-Ferrand, France \\ 6 Preventive and Occupational Medicine, University Hospital of Clermont-Ferrand, Clermont-Ferrand, France \\ 7 Australian Catholic University, Melbourne, Victoria, Australia \\ 8 Laboratoire Inter-Universitaire de Psychologie, Personnalité, Cognition et Changement Social (LIP/PC2S), Université Savoie Mont Blanc, Chambéry, \\ France \\ Corresponding Authors: Alicia Fournier, Laurie Mondillon \\ Email address: alicia.fournier@u-bourgogne.fr, laurie.mondillon@uca.fr
}

Background. Recent studies have shown that people with high alexithymia scores have decreased interoceptive abilities, which can be associated with psychological and physical disorders. Early assessments of the alexithymia trait included the evaluation of these abilities through the dimension measuring the difficulty in identifying and distinguishing between feelings and bodily sensations (the 26item Toronto Alexithymia Scale; TAS-26). However, the revised version of the TAS, the TAS-20, contains a three-factor solution that does not involve a dimension assessing interoceptive abilities. However, the 3 items allowing the evaluation of these abilities are still present in the TAS-20. In this context, we hypothesized that the 3 items which assess interoceptive abilities in the TAS-20 should constitute an independent factor. In addition to exploring the internal structure of the TAS-20, we examined its external validity by assessing the relationships between the new factors and self-reported measures of personality trait and psychological and physical health.

Method. Two online studies ( $\mathrm{N}=253$ and $\mathrm{N}=287$ ) were performed. The participants completed the TAS-20 and a set of psychological questionnaires (e.g., anxiety, depression) and health questions (e.g., "Do you suffer from a somatic disorder?"). The structure of the TAS-20 was examined using exploratory factor analysis (EFA), followed by an investigation of the relationships between the resulting new factors and other psychological and health data using regressions. In both studies, EFA revealed a new structure of the questionnaire consisting of four dimensions: (1) difficulty in the awareness of feelings, (2) externally oriented thinking, (3) difficulty in interoceptive abilities, and (4) poor affective sharing. The first factor was positively associated with all self-reported psychological and personality trait measures while the third factor was associated more with somatic disorders and medication intake.

Results. Our results suggest the presence of a new latent factor in the assessment of alexithymia that reflects interoceptive abilities specifically related to health and personality trait outcomes. In accordance with the results and the literature, it seems important to include an assessment of interoceptive abilities when considering the evaluation of alexithymia. The next step would be to develop a valid measure of these abilities.

Peer) reviewing PDF | (2019:03:36066:1:1:NEW 20 Jul 2019) 


\section{Importance of considering interoceptive abilities in alexithymia assessment}

4

5

6

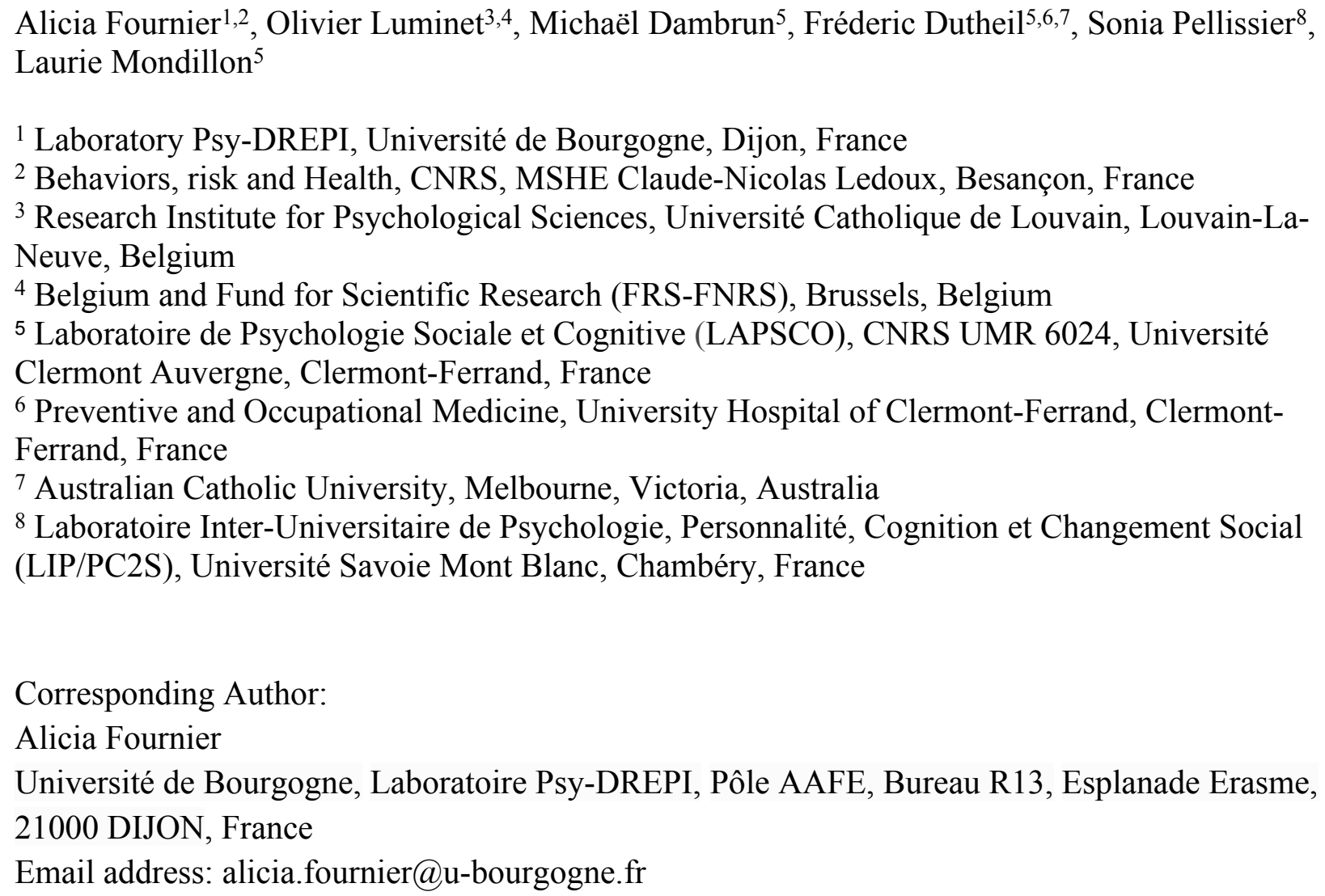

\section{Abstract}

Background. Recent studies have shown that people with high alexithymia scores have decreased interoceptive abilities, which can be associated with psychological and physical disorders. Early assessments of the alexithymia trait included the evaluation of these abilities through the dimension measuring the difficulty in identifying and distinguishing between feelings and bodily sensations (the 26-item Toronto Alexithymia Scale; TAS-26). However, the revised version of the TAS, the TAS-20, contains a three-factor solution that does not involve a dimension assessing interoceptive abilities. However, the 3 items allowing the evaluation of these abilities are still present in the TAS-20. In this context, we hypothesized that the 3 items which assess interoceptive abilities in the TAS-20 should constitute an independent factor. In addition to exploring the internal structure of the TAS-20, we examined its external validity by assessing the relationships between the new factors and self-reported measures of personality trait and psychological and physical health. 
43 Method. Two online studies ( $\mathrm{N}=253$ and $\mathrm{N}=287)$ were performed. The participants completed

44 the TAS-20 and a set of psychological questionnaires (e.g., anxiety, depression) and health 45 questions (e.g., "Do you suffer from a somatic disorder?"). The structure of the TAS-20 was

46 examined using exploratory factor analysis (EFA), followed by an investigation of the

47 relationships between the resulting new factors and other psychological and health data using

48 regressions.

49 In both studies, EFA revealed a new structure of the questionnaire consisting of four dimensions:

50 (1) difficulty in the awareness of feelings, (2) externally oriented thinking, (3) difficulty in

51 interoceptive abilities, and (4) poor affective sharing. The first factor was positively associated

52 with all self-reported psychological and personality trait measures while the third factor was

53 associated more with somatic disorders and medication intake.

54 Results. Our results suggest the presence of a new latent factor in the assessment of alexithymia

55 that reflects interoceptive abilities specifically related to health and personality trait outcomes. In

56 accordance with the results and the literature, it seems important to include an assessment of

57 interoceptive abilities when considering the evaluation of alexithymia. The next step would be to

58 develop a valid measure of these abilities.

59

60 Introduction

61 The alexithymia construct, literally meaning "without words for feelings" (Apfel \& Sifneos,

62 1979) (p. 180), is derived from clinical observations of patients suffering from psychosomatic

63 disorders (MacLean, 1949; Marty \& De M'Uzan, 1963; Ruesch, 1948). Based on these

64 observations, three main features were defined for the alexithymia construct: $i$ ) difficulty

65 identifying and describing one's own feelings, ii) limited imaginative processes, and iii) an

66 externally oriented cognitive style (Apfel \& Sifneos, 1979; Nemiah \& Sifneos, 1970). Following

67 a review of the literature on alexithymia, the features "difficulty in distinguishing between

68 feelings and bodily sensations" and "social conformity" were added later (Taylor, Ryan, \&

69 Bagby, 1985).

70 Alexithymia is associated with many psychological and physical disorders, such as anxiety

71 (Karukivi, Tolvanen, Karlsson, \& Karlsson, 2015), depression (Li, Zhang, Guo, \& Zhang, 2015),

72 somatization (Brandt, Pintzinger, \& Tran, 2015), somatic complaints (Tominaga, Choi, Nagoshi,

73 Wada, \& Fukui, 2014), eating disorders (Jenkinson, Taylor, \& Laws, 2018), myocardial

74 infarction (Silva, Freitas, Moreira, Santos, \& Almeida, 2016), carotid atherosclerosis (Grabe et

75 al., 2010), and higher mortality rates (Tolmunen, Lehto, Heliste, Kurl, \& Kauhanen, 2010). For

76 this reason, alexithymia is a construct of interest in many theoretical models of health

77 psychology (Lumley, Neely, \& Burger, 2007). It is, therefore, necessary to correctly assess this

78 construct using reliable and valid measures. Different scales have been developed to evaluate the

79 alexithymia construct, such as the Beth Israel Hospital Questionnaire (Sifneos, 1973), the

80 Schalling-Sifneos Personality Scale (Apfel \& Sifneos, 1979), and the MMPI alexithymia scale

81 (Kleiger \& Kinsman, 1980), but they have inadequate psychometric qualities (Taylor et al.,

82 1985). Consequently, the 26-item Toronto Alexithymia Scale (TAS-26) was developed. This

Peer) reviewing PDF | (2019:03:36066:1:1:NEW 20 Jul 2019) 
83

84

85

86

87

88

89

90

91

92

93

94

95

96

97

98

99

100

101

102

103

104

105

106

107

108

109

110

111

112

113

114

115

116

117

118

119

120

121

122

scale assessed four dimensions: $i$ ) difficulty identifying and distinguishing between feelings and bodily sensations (DIDF), ii) difficulty describing feelings (DDF), iii) reduced daydreaming, and iv) externally oriented thinking (EOT) (Taylor et al., 1985). Due to problems with the compositional structure of the TAS, the revision of this scale led to the development of the 23item TAS (TAS-R), which assessed two dimensions: $i$ ) ability to distinguish between feelings and bodily sensations associated with emotional arousal and the ability to describe feelings to others, and ii) EOT (Taylor, Bagby, \& Parker, 1992). During this review, the reduced daydreaming dimension was suppressed due to low corrected item-total correlations with the full TAS and a negative correlation with the DIDF factor. In addition, the DIDF and DDF dimensions were merged into one dimension, and one item was replaced by a new one. Two EOT items were removed and five new items were added. Subsequently, due to social desirability response bias and a lack of inter-correlations between factors, the TAS was reviewed one more time, resulting in the 20-item TAS (TAS-20) (Bagby, Parker, \& Taylor, 1994; Taylor, Bagby, \& Parker, 2003). The DDF dimension was reintroduced as a distinct dimension. The DIDF dimension became a difficulty identifying feelings (DIF) dimension and two items were deleted. However, the two items which were removed did not refer to the body, and two other items related to interoception were retained. The notion of difficulty distinguishing between feelings and bodily sensations was therefore dropped in the DIF dimension. In addition, one item from the EOT was suppressed.

The TAS-20 is the most widely used scale for measuring alexithymia both in empirical research and for clinical assessment (Lane, Weihs, Herring, Hishaw, \& Smith, 2015; Sekely, Bagby, \& Porcelli, 2018). Despite the fact that the alexithymia concept covers more features, this scale assesses three dimensions: $i$ ) DIF, ii) DDF, and iii) EOT. The TAS-20 has good reliability and factorial validity in different languages and cultures (Taylor et al., 2003), and the threedimensional model is considered as the best fit (Bagby et al., 1994; Loas, Parker, Otmani, Verrier, \& Fremaux, 1997; Parker, Bagby, Taylor, Endler, \& Schmitz, 1993). However, several studies have reported, for various reasons, that the factor structure of this scale is not always consistent (e.g., Haviland \& Reise, 1996; Kooiman, Spinhoven, \& Trijsburg, 2002; Müller, Bühner, \& Ellgring, 2003). First, the EOT dimension might better reflect the social norms that guide emotional behaviors rather than a cognitive style of thinking (Dere et al., 2013). This probably leads to the lack of internal consistency of this dimension (Bressi et al., 1996; Taylor et al., 2003; Zhu et al., 2007). Second, the verbalization and the differentiation of feelings seem theoretically interconnected (Lane \& Schwartz, 1987), which explains why some studies found a unique factor that combines the DIF and DDF dimensions (Erni, Lötscher, \& Modestin, 1997; Kooiman et al., 2002; Loas, Otmani, Verrier, Fremaux, \& Marchand, 1996). Third, the lack of consistency could be due to the analysis performed (Loas et al., 2001). Indeed, most studies that have reported other solutions than the three-factor solution only used exploratory factorial analysis (EFA), which accounts more for the existence of alternative models (Loas et al., 2001), whereas the appropriate tool to confirm the three-factor solution seems to be confirmatory factorial analysis (CFA). Fourth, we assume that this could be due to the suppression of the 
123 difficulty distinguishing between feelings and bodily sensations label without the suppression of 124 items referring to bodily sensations. This rearrangement could lead to the existence of a latent

125 factor in the TAS-20, which could reflect the old structure of the TAS-26 and TAS-R.

126

\section{Overview}

128 Therefore, the aim of this paper was to examine the structure of the TAS-20 using EFA in a

129

130

131

132

133

134

135

136

137

138

139

140

141

142

143

144

145

146

147

148

149

150

151

152

153

154

155

156

157

158

159

160

161

162 subclinical population. Contrary to the opinion of Loas and collaborators (2001), we decided to use EFA and not CFA. In fact, the aim of this paper was not to validate or confirm the factor structure of this scale but to explore whether the TAS-20 contains a latent factor assessing interoceptive abilities. The use of CFA would have involved making choices based on theoretical data, which could influence the results of our exploratory studies. Two different versions of the TAS-20 are available in French. The first comprises items rated on a 4-point Likert scale (Bruchon-Schweitzer, 2002) and the second contains items rated on a 5-point Likert scale (Loas et al., 1996). There are no other differences between the two versions; one is the gold standard (5-point Likert scale) and the other is available in French, but is not widely used (4-point Likert scale). In the first study, the participants completed the French version of the TAS-20 with a 4point Likert scale and in the second study, the participants completed the French version of the TAS-20 with a 5-point Likert scale. In addition to exploring the internal structure of the TAS-20, we examined its external validity by assessing the relationships between the new alexithymia factors resulting from the EFA and personality trait and the indicators of psychological and physical health. Alexithymia "is a marker of atypical interoception" (Murphy, Brewer, Catmur, $\&$ Bird, 2017) (p. 48) and the link between alexithymia and interoception is currently receiving significant attention in the field, as shown by several articles published in recent years (Bornemann \& Singer, 2017; Brewer, Cook, \& Bird, 2016; Murphy, Catmur, \& Bird, 2018; Zamariola, Frost, Van Oost, Corneille, \& Luminet, 2019; Zamariola, Vlemincx, Corneille, \& Luminet, 2018). Difficulties in interoceptive abilities can be associated with psychological and physical impairments (Murphy et al., 2017), and moderately with an emotional instability, a feature of the neuroticism trait (Fiene, Ireland, \& Brownlow, 2018; Kanbara \& Fukunaga, 2016). For these reasons, we assumed that if a latent factor existed in the TAS-20 that assesses interoceptive abilities, it should be associated, like other alexithymia dimensions, with the presence of physical and psychological health problems and the personality trait (i.e., emotional instability). If alexithymia is also defined by difficulties in interoceptive abilities, and these difficulties are related to health disorders and personality trait, this will allow new ways of theoretical reflection to be explored in order to understand the mechanisms underlying the development of DIF and DDF and to consider new interventions to reduce the health impact of alexithymia. In particular, for some individuals, it may be that DIF and DDF are mediated by difficulties in interoceptive abilities, which are abilities essential to emotion knowledge (Luminet \& Zamariola, 2018). If individuals cannot correctly perceive and interpret their bodily sensations, they may have difficulty identifying and describing their feelings, but also regulating them when necessary. In the long term, this could have several impacts on an individual's well- 
163 being. We would like to point out that the purpose of this work is not to criticize the factorial

164

165

166

167

168

169

170

171

172

173

174

175

176

177

178

179

180

181

182

183

184

185

186

187

188

189

190

191

192

193

194

195

196

197

198

199

200

201

structure of the TAS-20, but rather to highlight the possible existence of a latent factor that could assess difficulties in interoceptive abilities, as stated in the earlier versions of the questionnaire (TAS-26 and TAS-R). The first aim of this paper was to perform exploratory factor analysis to investigate the possible existence of a latent factor that could assess difficulties in interoceptive abilities, as stated in the earlier versions of the questionnaire (TAS-26 and TAS-R). We carried out exploratory studies on the factorial structure of the TAS-20. We assumed that the TAS-20 contained a latent factor to assess individuals' interoceptive abilities during emotional arousal. The presence of this factor could reflect the initial structure of the TAS proposed by Taylor et al. (1985), which contained the DIDF factor. Additionally, based on the literature on interoception, we assumed that if there is a latent factor for assessing interoceptive abilities, it would be related to health and personality outcomes. In particular, it would be associated with high scores of depression, anxiety, perceived stress and emotional instability.

\section{Materials \& Methods}

\section{Participants and Ethics Statement}

Overall, 540 participants (Study 1: N=253; Study 2: N=287) were enrolled. We recruited 395 undergraduate psychology students (Study 1: 16 men, 92 women; mean age: 19.44 \pm 1.28 ; Study 2: 35 men, 252 women; mean age: 19.56 \pm 1.58 ) from Clermont Auvergne University (formerly Blaise Pascal University, Clermont-Ferrand, France). The other participants were recruited on a voluntary basis from the general population through social networks (61 men, 84 women; mean age: $37.26 \pm 14.03)$. Table 1 provides an overview of the descriptive statistics of the samples and the measures used in each study. The Ethics Committee in Clermont-Ferrand approved the study protocol (CPP SUD-EST 6, IRB00008526, 2015-CE23). The nature and potential risks of the study were fully explained to the participants. Written informed consent was obtained from each participant. The experimental data is available at https://osf.io/8kncz.

\section{Measures}

Alexithymia was assessed using the 20-item Toronto Alexithymia Scale (TAS-20) (Bagby et al., 1994). The 20 items of this scale evaluate three dimensions of alexithymia: (a) difficulty identifying feelings (DIF) (items 1, 3, 6, 7, 9, 13,14) (Study 1: $\alpha=.81$; Study 2: $\alpha=.84$ ), (b) difficulty describing feelings (DDF) (items $2,4,11,12,17$ ) (Study 1: $\alpha=.80$; Study 2: $\alpha=.79$ ), and (c) externally oriented thinking (EOT) (items 5, 8, 10, 15, 16, 18, 19, 20) (Study 1: $\alpha=.65$; Study 2: $\alpha=.59$ ). Items $4,5,10,18$, and 19 are reverse coded. Two versions of the TAS-20 exist in French. In Study 1, we used the French version with items rated on a 4-point scale ranging from 1 (rarely) to 4 (very often) (Bruchon-Schweitzer, 2002). The total score varies from 20 to 80 , with a high score indicating a high level of alexithymia $(\alpha=.83)$. In Study 2, we used the French version with items measured on a 5-point Likert scale (Loas et al., 1996) ranging from 1 (strongly disagree) to 5 (strongly agree). The total score varies from 20 to 100, with a high score

Peer) reviewing PDF | (2019:03:36066:1:1:NEW 20 Jul 2019) 
202 indicating a high level of alexithymia $(\alpha=.84)$. With the 4-point scale, a score $>49$ indicates an 203 alexithymic trait, and with the 5-point scale, a score $>61$ indicates an alexithymic trait.

204 Trait anxiety was assessed using the Trait subscale of the State-Trait Anxiety Inventory (STAI) 205 (Bruchon-Schweitzer \& Paulhan, 1993; Spielberger, Gorsuch, Lushene, Vagg, \& Jacobs, 1983) 206 consisting of 20 items measured on a scale ranging from 1 (almost never) to 4 (almost always). 207 Items $1,3,6,7,10,13,14,16$, and 19 are reverse coded. The overall score varies from 20 to 80 , 208 with higher scores indicating a high level of anxiety (Study 1: $\alpha=.91$; Study 2: $\alpha=.91$ ). A score $209>65$ is considered very high.

210 In Study 1, depressive symptomatology was assessed using the Depression subscale of the 211 Hospital Anxiety and Depression Scale (HADS-D) (Lépine, Godchau, \& Brun, 1985; Zigmond $212 \&$ Snaith, 1983). The 7 items of this scale use a 4-point scale (from 0 to 3 ) to measure the 213 symptoms or behaviors that are often associated with depression. This scale was validated in a 214 variety of populations, including the general population, general practice and psychiatric patients 215 (Bjelland, Dahl, Haug, \& Neckelmann, 2002). The total score varies from 0 to 21, with a high 216 score indicating a high level of depressive symptomatology. A score $>8$ identifies those with a 217 positive history of depression. The HADS-D evaluates moderate depressive states; thus, it does 218 not mention suicidal ideation (Hansson, Chotai, Nordstöm, \& Bodlund, 2009) ( $\alpha=.73$ ). However, 219 in Study 2, we assessed the depression score using the Beck Depression Inventory-13 (BDI-13) 220 (Beck, Ward, Mendelson, Mock, \& Erbaugh, 1961; Collet \& Cottraux, 1986). The 13 items of 221 this scale measure the depression symptomatology on a 4-point scale from 0 to 3 . The total score 222 varies from 0 to 39, with a high score indicating a high level of depressive symptomatology $223(\alpha=.79)$. A score $\geq 30$ indicates severe depression. Because the BDI-13 contains an item on 224 suicidal ideologies, we were not permitted, for ethical reasons, to use this scale in Study 1, which 225 226

227

228

229

230

231

232

233 included individuals from the general population.

Emotional instability was measured using the Neuroticism dimension of the Big Five Inventory (BFI-N)(John, Donahue, \& Kentle, 1991; Plaisant, Courtois, Réveillère, Mendelsohn, \& John, 2010). The neuroticism trait is defined by negative affectivity, such as emotional instability, anger, worry, and sadness (Weiss \& Costa, 2005). Moreover, this trait is positively associated with alexithymia and somatization (Porcelli \& Taylor, 2018). The neuroticism dimension comprises 8 items rated on a 5-point scale ranging from 1 (not agree at all) to 5 (completely agree). Items 9, 24, and 34 are reverse coded. The total score varies from 5 to 40, with a high total score indicating a high emotional instability (Study 1: $\alpha=.85$; Study 2: $\alpha=.84$ ). As the BFI is not a diagnostic instrument, there is no cut-off.

235 Perceived stress was evaluated using the Perceived Stress Scale (PSS) (Bellinghausen, Collange, 236 Botella, Emery, \& Albert, 2009; Cohen \& Williamson, 1988). The 10 items of this scale measure 237 the degree to which everyday life situations are appraised as stressful on a 5-point scale ranging 238 from 0 (never) to 4 (very often). Items 4, 5, 7, and 8 are reverse coded. The total score varies 239 from 0 to 40, with a high score indicating a high level of perceived stress (Study 1: $\alpha=.88$; Study $2402: \alpha=.89$ ). As the PSS is not a diagnostic instrument, there is no cut-off. 
241 Coping strategies were assessed using the Brief Cope (Carver, 1997; Muller \& Spitz, 2003). The 24228 items of this scale measure fourteen coping strategies on a 4-point scale ranging from 1 (not 243 at all) to 4 (absolutely). Due to a large number of coping styles, and in accordance with Muller 244 and Spitz (2003), we grouped them into three categories: (a) functional coping (mean of active 245 coping, planning, positive reframing, and acceptance) (Study 1: $\alpha=.86$; Study 2: $\alpha=.80$ ), (b) 246 dysfunctional coping (mean of denial, behavioral disengagement, substance use, and self-blame) 247 (Study 1: $\alpha=.73$; Study 2: $\alpha=.70$ ), and (c) coping with varying functionality (mean of self248 distraction, humor, venting, use of emotional support, use of instrumental support, and religion) 249 (Study 1: $\alpha=.81$; Study 2: $\alpha=.72$ ). Coping with varying functionality are strategies that are less 250 likely to be delimited as functional or dysfunctional because they depend on the circumstances.

251

252

253

254

255

256

257

258

259

260

261

262

263

264

265

266

267

268

269

270

271

272

273

274

275

276

277

278

279

280

For example, use of emotional support can either help or harm the resolution of a stressful situation (Montgomery, Demers, \& Morin, 2010). For these reasons, these coping strategies were not used in subsequent analyses. We then created a difference score between functional and dysfunctional coping (F-D) to highlight the use of appropriate and effective strategies. This score suggests that the larger and more positive the difference between the scores, the more individuals use functional coping strategies, and the larger and more negative the difference between scores, the more individuals use dysfunctional coping.

Other health assessments. Participants were asked if they were currently under medical treatment. Individuals who reported medication intake had to specify the type of medication. In addition, when the participants completed the survey they were asked if they currently had cardiovascular disease or hypertension, chronic visceral disease or a somatic disorder (e.g., eczema, asthma, headaches, somatoform disorders, colitis), or an eating disorder. Medication intake, cardiovascular diseases, somatic disorders, and eating disorders were measured on a binary scale coded as 1 (yes) and 0 (no). These data were treated in a qualitative way.

\section{Procedure}

After providing informed consent, the participants completed a set of online questionnaires via the LimeSurvey platform. The students completed the protocol at the university while individuals from the general population completed the surveys at home. All participants completed the questionnaires in the following order: 1) STAI-T, 2) TAS-20, 3) HADS-D (Study 1) /BDI-13 (Study 2), 4) BFI-N, 5) PSS, and 6) Brief cope. Finally, the participants had to complete the four binary questions about health measures and demographic data.

\section{Statistical analysis}

First, we performed descriptive statistics of the health and psychological data. The aim of this paper was not to compare the samples with each other but to verify whether our results were consistent across studies. However, for information purposes, comparative analyses were performed using ANOVAs to check for differences between samples in socio-demographic, psychological, and health measures. To compare alexithymia scores between samples, we

Peer) reviewing PDF | (2019:03:36066:1:1:NEW 20 Jul 2019) 
281

282

283

284

285

286

287

288

289

290

291

292

293

294

295

296

297

298

299

300

301

302

303

304

305

306

307

308

309

310

311

312

313

314

315

316

317

318

319

320

transformed the 4-point Likert scale used in Study 1 to a 5-point Likert scale for each item and calculated the dimensions of alexithymia (i.e., DIF, DDF, EOT). For the depression score, we used two different scales (depression subscale of HADS in Study 1 and BDI-13 in Study 2) that assess different features of depression; therefore, we could not compare depression scores between samples. When the homoscedasticity assumption was violated, we used adjusted Welch's $F$. We performed Pearson chi-square tests to compare gender and health data between studies.

We performed an EFA with direct Oblimin rotation and principal axis factoring to examine the factorial structure of the TAS-20. To verify the sampling adequacy for the analysis, we computed the Kaiser-Meyer-Olkin (KMO) values for all individual items. For each factor, we estimated the internal consistency using Cronbach's alpha. Based on those results, in both Study 1 and Study 2, we decided to omit items 16 and 20, which belonged to a factor with very low reliability. These two items represent the preference for entertainment rather than an exploration of a deeper meaning in movies or plays. We then conducted another EFA to examine the structure of the remaining 18 items, and we called the resulting factors the "latent factors" (LF). Any items with component loadings $<.30$ were considered as explaining only a small part of the factor (Field, 2013). We decided not to report the value of these component loadings in the Tables unless items explained the factor. Reliability analysis was carried out for each component. We considered Cronbach's alphas $<.50$ as not satisfactory (Taber, 2017).

Finally, we performed multivariate regression analyses to examine whether the LFs were predictive of the psychological and health measures. Specifically, we conducted multivariate logistic regressions on each (binomial) health-related measure (somatic disorders, eating disorders, cardiovascular diseases, and medication intake), and multivariate linear regressions on each psychological measure (anxiety, depression, emotional instability, perceived stress, and coping strategies).

Statistical analysis was carried out using SPSS version 24.0 for Macintosh (Statistical Package for the Social Sciences, IBM Corporation, NY, USA). The $p$-value for statistical significance was set at $p<.05$, and the trend for significance was set at $p<.07$.

\section{Results}

Descriptive statistics are presented in Table 1. When comparing samples from Study 1 and Study 2 , we found that the participants in Study 2 included more women $\left(\chi^{2}\right.$ Pearson $(1)=27.21$, $p<.001)$ and younger $($ Welch $F(1,257.83)=133.29, p<.001)$, more anxious $(\mathrm{F}(1,538)=16,52$, $p<.001)$, emotionally more unstable $(F(1,538)=19.28, p<.001)$ individuals who perceived more stress $(F(1,538)=17.06, p<.001)$ and used more dysfunctional coping strategies $(F(1,538)=6.99$, $p=.008)$ compared to participants in Study 1. Moreover, the participants in Study 2 scored higher on alexithymia (TAS-20) compared to participants in Study $1(F(1,538)=9.58 ; p=.002)$ and had more difficulty identifying $($ Welch $F(1,532.23)=57.35 ; p<.001)$ and describing feelings $(F(1,538)=19.92 ; p<.001)$. However, the participants in Study 2 had less externally oriented thinking compared to the participants in Study $1(F(1,538)=42.09 ; p<.001)$. 
321 For more information on the recruited population, we also reported the number of individuals

322

323

324

325

326

327

328

329

330

331

332

333

334

335

336

337

338

339

340

341

342

343

344

345

346

347

348

349

350

351

352

353

354

355

356

357

358

359

360

with psychological disorders. In Study 1, 34 participants were considered alexithymic (>49) $(M=54.06 \pm 4.42), 18$ participants had a positive history of depression $(>8)(M=10.89 \pm 2.99)$, and 3 participants had a very high anxiety score $(>65)(M=71.67 \pm 5.51)$. In Study 2, 64 participants were considered alexithymic $(>61)(M=67.22 \pm 4.44), 10$ participants had a severe depression $(\geq 30)(M=30.9 \pm 1.29)$, and 6 participants had a very high anxiety score $(>65)(M=67.17 \pm 1.94)$. [Insert Table 1]

\section{Exploratory Factor Analysis of the TAS-20}

In Study 1, the KMO verified the sampling adequacy for the analysis $(K M O=.85$; individual $K M O$ values $\geq .55$ and $\leq .94$ ). The Kaiser criterion indicated five factors (F1 to F5), which accounted for $57.54 \%$ of the total variance. $\mathrm{F} 1$ consisted of seven items (items $1,2,6,9,11,13,14 ; \alpha_{1}=.85$ ), F2 consisted of five items (items $5,8,10,18,19 ; \alpha_{2}=.62$ ), F3 consisted of two items (items 3,$7 ; \alpha_{3}=.66$ ), F4 consisted of two items (items 16, 20; $\alpha_{4}=.36$ ), and F5 consisted of four items (items $4,12,15,17 ; \alpha_{5}=.68$ ) (Table 2).

$\mathrm{F} 4$, which included item 16 (A preference for entertainment shows rather than psychological dramas) and item 20 (A preference not to search for the hidden meanings of films or plays in order to not distract from the pleasure), had very low reliability $\left(\alpha_{4}=.36\right)$. Therefore, we conducted another EFA without these items. The KMO verified the sampling adequacy $(K M O=.87$; individual $K M O$ values $\geq .66$ and $\leq .90$ ). The results revealed a new structure with four latent factors, LF1 (items 1, 2, 6, 9, 11, 13, 14; $\alpha_{1}=.85$ ), LF2 (items 5, 8, 10, 18, 19; $\alpha_{2}=.62$ ), LF3 (items 3,$7 ; \alpha_{3}=.66$ ), and LF4 (items $4,12,15,17 ; \alpha_{4}=.68$ ), which accounted for $56 \%$ of the total variance. This reallocation was conceptually relevant, since LF1 (5 items of DIF and 2 items of DDF) referred to difficulty in the awareness of feelings, LF2 (5 items of EOT) referred to externally oriented thinking, LF3 ( 2 items of DIF) referred to difficulty in interoceptive capacities, and LF4 (3 items of DDF and 1 item of EOT) referred to poor affective sharing (Table 2).

[Insert Table 2]

In Study 2, the KMO verified the sampling adequacy for the analysis $(K M O=.86$; individual $K M O$ values $\geq .59$ and $\leq .92$ ). The Kaiser criterion indicated six factors (F1 to F6), which accounted for $62.57 \%$ of the total variance. F1 consisted of seven items (items 1, 2, 4, 6, 9, 13, 14; $\alpha_{1}=.88$ ), F2 consisted of three items (items 10, 18, 19; $\alpha_{2}=.51$ ), F3 consisted of four items (items $11,12,15,17 ; \alpha_{3}=.70$ ), F4 consisted of three items (items $3,7,13^{2} ; \alpha_{4}=.71$ ), F5 consisted of two items (items 16, 20; $\alpha_{5}=.43$ ), and F6 consisted of two items (items 5, 8; $\alpha_{6}=.37$ ) (Table 3). F5, which included item 16 (A preference for entertainment shows rather than psychological dramas) and item 20 (A preference not to search for the hidden meanings of films or plays in order not to distract from the pleasure), had a low reliability $\left(\alpha_{5}=.43\right)$ and seemed to have limited relevance to the alexithymia trait. Hence, we decided to omit them. Moreover, F6, which

Peer) reviewing PDF | (2019:03:36066:1:1:NEW 20 Jul 2019) 
361

362

363

364

365

366

367

368

369

370

371

372

373

374

375

376

377

378

379

380

381

382

383

384

385

386

387

388

389

390

391

392

393

394

395

396

397

398

399

included item 5 (A preference to analyze problems rather than describe them) and item 8 ( $A$ preference to let things happen rather than to understand) also had very low reliability $\left(\alpha_{6}=.37\right)$. However, these items seemed to be representative of the alexithymia trait. Because alexithymia reflects a tendency to focus on the concrete details of external events rather than on feelings, suppressing them would have been against the theory. Therefore, we decided to keep them. As in Study 1, we conducted another EFA without items 16 and 20. The KMO verified the sampling adequacy $(K M O=.87$; individual $K M O$ values $\geq .59$ and $\leq .92)$. The results showed a new structure with five factors, F1 (items 1, 2, 4, 6, 9, 14; $\alpha_{1}=.86$ ), F2 (items 5, 8, 10, 18, 19; $\alpha_{2}=.51$ ), F3 (items 11, 12, 15, 17; $\alpha_{3}=.70$ ), F4 (items 3, 7, 13; $\alpha_{4}=.71$ ), and F5, which did not have dominant items. This structure accounted for $60.94 \%$ of the total variance. Due to the absence of factor loading on the F5, we decided to conduct another EFA by forcing the factorization to four latent factors. The KMO verified the sampling adequacy for the analysis $(K M O=.87$; individual $K M O$ values $\geq .59$ and $\leq .92)$. LF1 consisted of seven items (items $1,2,4$, $6,9,13,14 ; \alpha_{1}=.88$ ), LF2 consisted of five items (items 5, 8, 10,18, 19; $\alpha_{2}=.51$ ), LF3 consisted of two items (items 3,$7 ; \alpha_{4}=.64$ ), and LF4 consisted of four items (items $11,12,15,17 ; \alpha_{3}=.70$ ), which accounted for $55.27 \%$ of the total variance. Parameter estimates from the EFA are presented in Table 3. This reallocation was conceptually relevant, since LF1 (5 items of DIF and 2 items of DDF) referred to difficulty in awareness of feelings, LF2 (5 items of EOT) referred to externally oriented thinking, LF3 (2 items of DIF) referred to difficulty in interoceptive capacities, and LF4 (3 items of DDF and 1 item of EOT) referred to poor affective sharing (Table 3).

\section{[Insert Table 3]}

In both studies, the four resultant factors of our analyses seemed to evaluate a difficulty in awareness of feelings, an externally oriented thinking, interoceptive capacities, and a poor affective sharing. The only main difference between Study 1 and Study 2 concerned items 4 and 11. Item 4, which refers to the capacity to describe one's own feelings, loaded on LF4 (poor affective sharing) in Study 1 and on LF2 (externally oriented thinking) in Study 2. The opposite pattern was observed for item 11, which refers to the capacity to describe one's feelings about others. Moreover, both items 5 and 8 loaded on LF2 in Study 1, whereas they belonged to a separate factor with a low Cronbach alpha in Study 2. Therefore, it would have been statistically correct to suppress those items in Study 2, but we decided to keep them for theoretical reasons. Indeed, their meaning clearly reflects an external oriented thinking style, which is one of the features of alexithymia. However, the analyses showed that item 8 had a low correlation (.20) with the other items of LF2 in Study 1 (.20) and in Study 2 (.33). This item may therefore only be slightly representative of the alexithymia trait.

\section{Predictive Value of the Latent Factors}


400 The results of the four multivariate logistic regression analyses by study are reported in Table 4. 401 When entering all LFs as predictors, the models with both somatic disorders (Study 1:

$402 \chi^{2}(4)=11.09, p=.026$, Nagelkerke $R^{2}=.14$; Study $2: \chi^{2}(4)=22.38, p<.001$, Nagelkerke $\left.R^{2}=.26\right)$ and 403 medication intake (Study 1: $\chi^{2}(4)=13.71, p=.008, R^{2}=.10$; Study $2: \chi^{2}(4)=12, p=.017, R^{2}=.08$ ) 404 were significant in both studies. For eating disorders, the model was significant in both Study 1 $405\left(\chi^{2}(4)=11.07, p=.026, R^{2}=.09\right)$ and Study $2\left(\chi^{2}(4)=9.17, p=.057, R^{2}=.08\right)$. For cardiovascular 406 diseases, the model was only significant in Study 2 (Study 1: $\chi^{2}(4)=3.40, p=.493, R^{2}=.04$; Study $4072: \chi^{2}(4)=10.98, p=.027, R^{2}=.12$ ). LF1 positively predicted eating disorders in only Study 1 . LF2 408 was not a predictor of any of the parameters. In both studies, LF3 was positively predictive of

409

410

411

412

413

414

415

416

417

418

419

420

421

422

423

424

425

426

427

428

429

430

431

432

433

434

435

436

437

438

439 somatic disorders and medication intake, while in Study 2 it positively predicted eating disorders and cardiovascular diseases. Finally, LF4 negatively predicted medication intake in Study 1, although it was a trend in Study 2.

The results of the five multivariate linear regression analyses by study are reported in Table 5 . When entering all LFs as predictors, the models that included the anxiety trait score (Study 1: $F(4,248)=32.10, p<.001, R^{2}=.34$; Study $\left.2: F(4,282)=33, p<.001, R^{2}=.32\right)$, the depression score (Study 1: $F(4,248)=23.16, p<.001, R^{2}=.27$; Study 2: $F(4,282)=21.03, p<.001, R^{2}=.23$ ), the emotional instability score (Study 1: $F(4,248)=17.25, p<.001, R^{2}=.22$; Study 2: $F(4,282)=22.12$, $p<.001, R^{2}=.24$ ), the perceived stress score (Study 1: $F(4,248)=21.91, p<.001, R^{2}=.26$; Study 2: $\left.F(4,282)=23.67, p<.001, R^{2}=.25\right)$, and the coping difference score (Study 1: $F(4,248)=21.47$, $p<.001, R^{2}=.26$; Study 2: $\left.F(4,282)=21.97, p<.001, R^{2}=.24\right)$ were significant in both studies. In both studies, LF1 was positively associated with all measures (anxiety, depression, emotional instability, perceived stress, and effective coping strategies). LF2 was positively associated with depression scores and negatively associated with effective coping strategies in Study 1, whereas LF2 approached significance in the negative prediction of effective coping strategies in Study 2. LF3 was positively associated with depression and perceived stress scores in both studies. LF3, however, was also positively associated with anxiety and emotional instability scores, and negatively associated with effective coping strategies in Study 2, and approached significance in the positive prediction of the emotional instability scores and in the negative prediction of effective coping strategies in Study 1. Finally, LF4 was negatively associated with emotional instability scores in both studies. We discuss those relationships in the general discussion. The results of the all regression analyses are reported in Figure 1.

\section{[Insert Table 4]}

[Insert Table 5]

[Insert Figure 1]

\section{General discussion}

The aim of the two studies was to examine the existence of a potential latent factor in the TAS- 
44020 structure. We also examined its external validity by investigating the relationships of the new 441 latent alexithymia factors with psychological, physical health and personality trait measures. As 442 expected, our results mainly highlight the presence of a new latent factor in the assessment of 443 alexithymia, which seems to reflect interoceptive abilities.

444 The EFA performed on the TAS-20 showed the existence of factors that did not strictly refer to 445 the theoretical factors mentioned in the literature (Bagby et al., 1994; Taylor et al., 2003).

446

447

448

449

450

451

452

453

454

455

456

457

458

459

460

461

462

463

464

465

466

467

468

469

470

471

472

473

474

475

476

477

478

479 Among these factors, items 16 and 20 had very low internal reliability. These items represent the preference for entertainment rather than an exploration of a deeper meaning in movies or plays, which appears to reflect social norms rather than a core alexithymia trait (Dere et al., 2013).

Moreover, previous studies have found that items 16 and 20 correlate weakly or not at all with the EOT subscale, suggesting that these items would not be the ideal candidates for the assessment of alexithymia (González-Arias, Martínez-Molina, Galdames, \& Urzúa, 2018; Kooiman et al., 2002). Therefore, we decided to remove them from the scale, which resulted in a new TAS consisting of 18 items. Furthermore, while items 5, 8, 10, 18, and 19 loaded on the same factor in Study 1, both items 5 and 8 emerged as separate single factors in Study 2, with very low internal reliability. Indeed, items 5 and 8 focus on problem-solving whereas the remaining items (i.e., 10,18,19) focus on emotions, which could explain why they did not load on the same factor in the first EFA in Study 2. These two items, however, represent a concrete cognitive style and seem to be representative of the alexithymia trait. Based on these considerations, suppressing them would have been against the theory, so we decided to retain them. Despite this, correlations between item 8 and the other items loading on the same factor were still low $(<.30)$, so it may be more appropriate to reconsider its place in the evaluation of alexithymia or to rewrite it. In addition, because the aim of this paper was not to validate or confirm the factor structure of this scale but to explore whether the TAS-20 contains a latent factor assessing interoceptive abilities, we will not discuss the validity of this factor. However, it is possible that the presence of items 16 and 20 may explain the lack of internal consistency of this dimension (Bressi et al., 1996; Taylor et al., 2003; Zhu et al., 2007).

Our results mainly highlight the presence of new latent factors in the assessment of alexithymia. Interestingly, those factors were present in an earlier structure of the TAS, originally called TAS26 (Taylor et al., 1985). We found that in the present structure, LF1 (difficulty in awareness of feelings) always included items from the DIF/DDF dimensions of the TAS-20, and all of these items belonged to the previous capacity to identify and to distinguish between feelings and bodily sensations present in the TAS-26. Furthermore, LF2 (externally oriented thinking) included the same items from the EOT dimension in both studies, three of which previously belonged to the old preference for focusing on external events rather than inner experiences dimension of the TAS-26. The remaining two items were created after the TAS-26 review. This clustering is consistent with previous works supporting an oblique two-dimensional model in which DIF and DDF belonged to the same factor while EOT formed a single factor (Erni et al., 1997; Kooiman et al., 2002; Loas et al., 1996). Moreover, the authors also proposed this clustering for the TAS-R version (Taylor et al., 1992). We found associations between LF1 (difficulty in awareness of 
480 feelings, grouping DIF and DDF items) and all psychological outcomes, emotional instability 481 and with the use of copying strategies that are mostly maladaptive. High scores in the DIF or 482 DDF dimensions can be associated with poor emotion regulation, which is linked with mental 483 health alterations (Luminet \& Zamariola, 2018). Cutuli (2014) proposed that higher scores in the 484 DDF dimension are associated with higher levels of expressive suppression, which is considered 485 as a maladaptive regulation strategy, and that this strategy is associated with stronger depressive symptoms, lower interpersonal functioning, and decreased levels of well-being. In addition, higher scores in the DIF factor scale were related to limited use of emotion regulation strategies and the DDF or DIF-depression relationships were mediated by experiential avoidance, a tendency to avoid negative internal experiences (sensations, emotions, thoughts, memories) (Hayes et al., 2004). In the present paper, these associations between LF1 and psychological outcomes support the idea of an ineffective emotion regulation in individuals suffering from an overall decrease in awareness of feelings. Moreover, the negative association of LF2 with effective coping strategies in both studies suggests that it is difficult for alexithymic people to cope with difficult situations, which reflects their deficits in emotion regulation (Luminet \& Zamariola, 2018). These results are highly consistent with the literature, since deficits in emotion regulation have been well documented in people with alexithymia (Luminet \& Zamariola, 2018;

498

499

500

501

502

503

504

505

506

507

508

509

510

511

512

513

514

515

516 Lumley et al., 2007). In spite of this empirical evidence, grouping DIF and DDF dimensions was not consistent in the literature, since this clustering depends on the types of statistical tools chosen (EFA vs. CFA), although a three-dimensional model (i.e., DIF, DDF, EOT) is still considered as the best fit (Loas et al., 2001).

As expected, our results confirmed the existence of a new latent factor in the assessment of alexithymia, which seems to reflect interoceptive abilities. The LF3 (difficulty in interoceptive abilities) included two items $\left(3^{1}\right.$ and $\left.7^{2}\right)$ from the DIF dimension of the TAS-20. These are the only items that explicitly refer to physical and bodily sensations and therefore reflect the presumed clustering of awareness of feelings and interoceptive abilities. In the TAS-26, these items were again part of the capacity to identify and to distinguish between feelings and bodily sensations. Even if later scale development of the TAS excluded the specific assessment of difficulty in distinguishing between feelings and bodily sensations, some items, which still evaluated this feature (items 3 and 7), were included in the TAS-20 review. The present research thus supports the existence of an independent latent dimension permitting the assessment of this ability. This finding is quite consistent with the literature indicating an atypical interoception in alexithymic individuals (Murphy et al., 2017). Interoception is composed of three dimensions: $i$ ) interoceptive sensibility (IS) (subjective abilities to report on body states); ii) interoceptive accuracy (IAcc) (objective abilities to perceive internal body changes); iii) interoceptive awareness (degree of overlap between IAcc and IS) (Pollatos \& Herbert, 2018). A fourth dimension has recently been proposed, the emotional evaluation of interoceptive signals. This

\footnotetext{
${ }^{1}$ Item 3: "I have physical sensations that even doctors don't understand".

2 Item 7: "I am often puzzled by sensations in my body".
} 
517 dimension refers to the emotional degree attributed to the bodily sensations that are expressed or 518 taken into account in a specific situation (Pollatos \& Herbert, 2018). The study of the

519 relationship between alexithymia and dimensions of interoception is currently receiving

520 considerable attention. However, the studies are contradictory. Some studies show a link

521 between alexithymia and IAcc (Herbert, Herbert, \& Pollatos, 2011; Murphy et al., 2018; Shah,

522 Hall, Catmur, \& Bird, 2016) and IS (Brewer et al., 2016), while others show a weak correlation

523 between IS and alexithymia (Zamariola et al., 2018) and no relationship with IAcc (Bornemann

524 \& Singer, 2017; Zamariola et al., 2018). One explanation for this disparity could be the choice of

525 tools. Currently, the validity of the task most commonly used to measure IAcc, the Heartbeat

526 Tracking task (Schandry, 1981), is being questioned by various authors (e.g., Desmedt, Luminet, 527 \& Corneille, 2018; Ring, Brener, Knapp, \& Mailloux, 2015). In addition, this task focuses on

528 only the perception of heart rate and does not consider the ability to perceive other internal body 529 sensations of interoception. Also, IS measures face the usual limitations of self-reporting and the 530 questionnaires used to measure these abilities are very different from one study to another (e.g.,

531 Brewer et al., 2016; Zamariola et al., 2018). Moreover, in view of the present results, we can

532 speculate that alexithymic individuals do not present difficulties in perceiving or reporting

533 internal body sensations, but rather a difficulty in interpreting body sensations. This could

534 correspond to the fourth dimension proposed by Herbet and Pollatos (2018), the emotional

535 evaluation of interoception signals, and would be consistent with the positive relationship

536 between alexithymia and a perception of similarity between emotional and non-emotional states

537 (Brewer et al., 2016). New studies are needed to further develop this hypothesis. As observed in

538 alexithymia, such an atypical functioning, in association with an alteration of emotional

539 awareness, could lead in the long run to the development of psychosomatic diseases (Kanbara \&

540 Fukunaga, 2016; Porcelli \& Taylor, 2018). It also corroborates our results that showed a positive

541 association between this dimension and the presence of somatic diseases. In both studies,

542 individuals with high scores on LF3 (difficulty in interoceptive awareness) were more likely to

543 exhibit somatic disorders and to take medications compared to those with low scores. Study 2

544 showed that LF3 could also be related to cardiovascular diseases. To our knowledge, few studies

545 have shown the link between coronary heart disease and interoception (Kollenbaum, 1994).

546 According to the present results, this study mentions that patients with coronary heart disease

547 generally underestimate their heart rate. However, high levels of alexithymia are found in

548 patients with cardiovascular disease, particularly those with hypertension (Porcelli \& Taylor,

549 2018). Since the TAS-20 contains a latent factor for measuring interoceptive abilities, it may be

550 that these associations with alexithymia are due to the presence of this latent factor. Further

551 studies are needed to further develop this hypothesis. Regarding psychological issues,

552 individuals with high scores for LF3 were more likely to exhibit eating disorders, high emotional

553 instability scores, and dysfunctional coping strategies. Therefore, it is important not to neglect

554 the evaluation of this interoceptive dimension, considering that it could allow the referral of

555 alexithymic individuals to the appropriate therapies in the fields of somatic and psychological

556 health. In addition to promoting the recognition and regulation of feelings for individuals with 
557 high scores in LF1 (Thoma \& Greenberg, 2015), proposing therapies based mainly on the

558

559

560

561

562

563

564

565

566

567

568

569

570

571

572

573

574

575

576

577

578

579

580

581

582

583

584

585

586

587

588

589

590

591

592

593

594

595

596

processing of interoceptive signals emanating from the body could constitute a new perspective for preventive health programs in patients with high LF3 scores. With this in mind, the LF3 subscale would benefit from supplementary items dealing with interoception.

LF4 (poor affective sharing) included items from the DDF/EOT dimensions of the TAS-20. Two of them belonged to the difficulty describing feelings dimension of the TAS-26, which refers to the ability to communicate feelings to other people, and the other items were created during the TAS-26 review. The main difference between Study 1 and Study 2 concerned items 4 and 11. In Study 1, item 4 belonged to LF4 and item 11 to LF1 while in Study 2, it was the opposite. Interestingly, these two items also belonged to two axes in TAS-26. They were used to assess both the capacity to identify and to distinguish between feelings and bodily sensations and the ability to communicate feelings to other people. These two items may, therefore, be ambiguous, even if they belonged to the DDS dimension in TAS-20. Finally, LF4 (poor affective sharing) was negatively associated with emotional instability scores and medication intake. Since we performed multivariate regression analyses, the predictive effect of LF4 was analyzed in the unique context of social-affective sharing, thereby controlling for the effect of the other LFs. The predictive effect of LF4 might, therefore, reveal that the least emotionally stable individuals are less likely to feel the need to share their emotions and affects with others. In such a context, high scores in LF4 could predict low levels of emotional instability and medication intake.

Limits

Some limitations should be mentioned. First, the four health measures were collected using binomial self-report questions. It would be interesting to replicate our results using structured interviews and/or validated questionnaires. Second, the recruited population was a subclinical population, so it was not possible to generalize about the relationship between alexithymia and clinical symptomatology. This population was composed of individuals from the general population and students. While in Study 1 we had both individuals from the general population and students, in Study 2 we had only students. Additionally, we used two different depression scales and two different alexithymia scales, although there are no significant differences between the two versions apart from the Likert scale. As a consequence, the groups are difficult to compare. Third, we had to recruit students to complete our sample for Study 1 because we could not get enough participants from the general population. Finally, in this paper, the studies conducted are transversal and not longitudinal. Thus, we cannot conclude if alexithymia is a common co-occurring or a primary pathology. The impact of alexithymia on health and its etiology are difficult to understand because it requires longitudinal studies to know its causal relationships and origin. Some authors postulate that alexithymia is an inherited trait, others mention that alexithymia follows a deficit in the development of affects during childhood, or even postulate that it is a defense mechanism put in place to deal with negative emotions that are difficult for individuals to overcome. However, a multifactorial etiology is strongly suggested and could be the result of a combination of environmental and genetic factors (for review see

PeerJ reviewing PDF | (2019:03:36066:1:1:NEW 20 Jul 2019) 
597 Taylor \& Bagby, 2013). From a clinical perspective, it is important to know the etiology of 598 alexithymia and its role on health. To ensure this, longitudinal studies must be considered.

599

600 Conclusions

601 Despite the fact that we used TAS-20 versions measured using a 4-point scale in Study 1 and on 602 a 5-point scale in Study 2, we found a very similar distribution of items across both studies. The 603 latent structure of the TAS-20 reflects a substantial part of the older structure of the scale.

604 Strikingly, one of those latent factors is linked to an important concept from the TAS-26: the 605 interoceptive abilities. Its associations with somatic issues highlight the key role of the body

606 awareness component in alexithymia, which is currently neglected in the evaluation of this 607 construct. The alexithymia scale with a full dimension covering interoceptive abilities would 608 open new possibilities in the research field of alexithymia. From a health perspective, this could 609 also contribute to better management of alexithymic individuals, as it would allow health 610 professionals to refer them to the most appropriate preventive therapies.

611

612 Acknowledgments

613 The authors are grateful to the participants who took part in the studies.

614

615

616

617

618

619

620

621

622

623

624

625

626

627

628

629

630

631

632

633

634

635

636

637

\section{References}

Apfel, R. J., \& Sifneos, P. E. (1979). Alexithymia: Concept and measurement. Psychotherapy and Psychosomatics, 32(1-4), 180-190. https://doi.org/10.1159/000287386

Bagby, R. M., Parker, J. D. A., \& Taylor, G. J. (1994). The twenty-item Toronto Alexithymia Scale-I. Item selection and cross-validation of the factor structure. Journal of Psychosomatic Research, 38(1), 23-32. https://doi.org/10.1016/0022-3999(94)90005-1

Beck, A. T., Ward, C. H., Mendelson, M., Mock, J., \& Erbaugh, J. (1961). An inventory for measuring depression. Archives of General Psychiatry, 4(6), 561-571. https://doi.org/10.1001/archpsyc.1961.01710120031004

Bellinghausen, L., Collange, J., Botella, M., Emery, J.-L., \& Albert, E. (2009). Validation factorielle de l'échelle française de stress perçu en milieu professionnel [Factorial validation of the French Perceived Stress Scale in the workplace]. Sante Publique, 21(4), 365-373. Retrieved from http://www.cairn.info/revue-sante-publique-2009-4-page-365.htm

Bjelland, I., Dahl, A. A., Haug, T. T., \& Neckelmann, D. (2002). The validity of the Hospital Anxiety and Depression Scale. An updated literature review. Journal of Psychosomatic Research, 52(2), 69-77. Retrieved from http://www.ncbi.nlm.nih.gov/pubmed/11832252

Bornemann, B., \& Singer, T. (2017). Taking time to feel our body: Steady increases in heartbeat perception accuracy and decreases in alexithymia over 9 months of contemplative mental training. Psychophysiology, 54(3), 469-482. https://doi.org/10.1111/psyp.12790

Brandt, L., Pintzinger, N. M., \& Tran, U. S. (2015). Abnormalities in Automatic Processing of Illness-Related Stimuli in Self-Rated Alexithymia. PLOS ONE, 10(6), e0129905. https://doi.org/10.1371/journal.pone.0129905

Bressi, C., Taylor, G. J., Parker, J. D. A., Bressi, S., Brambilla, V., Aguglia, E., ... Invernizzi, G. 
638

639

640

641

642

643

644

645

646

647

648

649

650

651

652

653

654

655

656

657

658

659

660

661

662

663

664

665

666

667

668

669

670

671

672

673

674

675

676

677

678

679

680

681

682

683

(1996). Cross validation of the factor structure of the 20-item Toronto Alexithymia Scale: An Italian multicenter study. Journal of Psychosomatic Research, 41(6), 551-559. https://doi.org/10.1016/S0022-3999(96)00228-0

Brewer, R., Cook, R., \& Bird, G. (2016). Alexithymia: a general deficit of interoception. $R$ Soc Open Sci., 3(10), 150664. https://doi.org/10.1098/rsos.150664

Bruchon-Schweitzer, M. (2002). La personnalité comme facteur de vulnérabilité. In M. BruchonSchweitzer (Ed.), Psychologie de la santé. Modèles, concepts et méthodes (Dunod, pp. 161218). Paris, France.

Bruchon-Schweitzer, M., \& Paulhan, I. (1993). Manuel de l'Inventaire d'Anxiété État-Trait forme Y (STAI-Y) [Manual for the State-Trait Anxiety Inventory (Form Y)]. Paris, France: Les Editions du Centre de Psychologie Appliquée. Retrieved from http://www.sudoc.abes.fr/xslt/DB=2.1//SRCH?IKT=12\&TRM=03584650X

Carver, C. S. (1997). You want to measure coping but your protocol's too long: Consider the Brief COPE. International Journal of Behavioral Medicine, 4(1), 91-100. https://doi.org/10.1207/s15327558ijbm0401_6

Cohen, S., \& Williamson, G. M. (1988). Perceived stress in a probability sample of the United States. In S. Spacapam \& S. Oskamp (Eds.), The Social Psychology of Health (pp. 30-67). Newbury Park, CA: Sage. Retrieved from http://psycnet.apa.org/psycinfo/1988-98838-002

Collet, L., \& Cottraux, J. (1986). Inventaire abrégé de la dépression de Beck (13 items): Étude de la validité concurrente avec les échelles de Hamilton et de ralentissement de Widlöcher [The shortened Beck depression inventory (13 items). Study of the concurrent validity with the Hamilton. L'Encephale, 12(2), 77-79. Retrieved from http://www.ncbi.nlm.nih.gov/pubmed/3743520

Cutuli, D. (2014). Cognitive reappraisal and expressive suppression strategies role in the emotion regulation: an overview on their modulatory effects and neural correlates. Frontiers in Systems Neuroscience, 8, 175. https://doi.org/10.3389/fnsys.2014.00175

Dere, J., Tang, Q., Zhu, X., Cai, L., Yao, S., \& Ryder, A. G. (2013). The cultural shaping of alexithymia: Values and externally oriented thinking in a Chinese clinical sample. Comprehensive Psychiatry, 54(4), 362-368. https://doi.org/10.1016/j.comppsych.2012.10.013

Desmedt, O., Luminet, O., \& Corneille, O. (2018). The heartbeat counting task largely involves non-interoceptive processes: Evidence from both the original and an adapted counting task. Biological Psychology, 138, 185-188. https://doi.org/10.1016/j.biopsycho.2018.09.004

Erni, T., Lötscher, K., \& Modestin, J. (1997). Two-Factor Solution of the 20-ltem Toronto Alexithymia Scale Confirmed. Psychopathology, 30(6), 335-340. https://doi.org/10.1159/000285079

Field, A. (2013). Discovering Statistics Using IBM SPSS statistics (4th ed.). London: Sage. Fiene, L., Ireland, M. J., \& Brownlow, C. (2018). The Interoception Sensory Questionnaire (ISQ): A Scale to Measure Interoceptive Challenges in Adults. Journal of Autism and Developmental Disorders, 48(10), 3354-3366. https://doi.org/10.1007/s10803-018-3600-3

González-Arias, M., Martínez-Molina, A., Galdames, S., \& Urzúa, A. (2018). Psychometric Properties of the 20-Item Toronto Alexithymia Scale in the Chilean Population. Frontiers in Psychology, 9, 963. https://doi.org/10.3389/fpsyg.2018.00963

Grabe, H. J., Schwahn, C., Barnow, S., Spitzer, C., John, U., Freyberger, H. J., ... Völzke, H. (2010). Alexithymia, hypertension, and subclinical atherosclerosis in the general population. Journal of Psychosomatic Research, 68(2), 139-147.

Peer) reviewing PDF | (2019:03:36066:1:1:NEW 20 Jul 2019) 
684

685

686

687

688

689

690

691

692

693

694

695

696

697

698

699

700

701

702

703

704

705

706

707

708

709

710

711

712

713

714

715

716

717

718

719

720

721

722

723

724

725

726

727

728

729

https://doi.org/10.1016/j.jpsychores.2009.07.015

Hansson, M., Chotai, J., Nordstöm, A., \& Bodlund, O. (2009). Comparison of two self-rating scales to detect depression: HADS and PHQ-9. Br J Gen Pract, 56(566), e283-288. https://doi.org/10.3399/bjgp09X454070.

Haviland, M. G., \& Reise, S. P. (1996). Structure of the twenty-item Toronto Alexithymia Scale. Journal of Personality Assessment, 66(1), 116-125.

https://doi.org/10.1207/s15327752jpa6601_9

Hayes, S. C., Strosahl, K., Wilson, K. G., Bissett, R. T., Pistorello, J., Toarmino, D., ... McCurry, S. M. (2004). Measuring experiential avoidance: A preliminary test of a working model. The Psychological Record, 54(4), 553-578. https://doi.org/10.1007/BF03395492

Herbert, B. M., Herbert, C., \& Pollatos, O. (2011). On the relationship between interoceptive awareness and alexithymia: Is interoceptive awareness related to emotional awareness? Journal of Personality, 79(5), 1149-1175. https://doi.org/10.1111/j.14676494.2011.00717.x

Jenkinson, P. M., Taylor, L., \& Laws, K. R. (2018). Self-reported interoceptive deficits in eating disorders: A meta-analysis of studies using the eating disorder inventory. Journal of Psychosomatic Research, 110, 38-45. https://doi.org/10.1016/j.jpsychores.2018.04.005

John, O. P., Donahue, E. M., \& Kentle, R. L. (1991). The Big Five Inventory--Versions $4 a$ and 54. Berkeley, CA: University of California, Institute of Personality and Social Research. Retrieved from https://www.ocf.berkeley.edu/ johnlab/bfi.htm

Kanbara, K., \& Fukunaga, M. (2016). Links among emotional awareness, somatic awareness and autonomic homeostatic processing. BioPsychoSocial Medicine, 10(1), 16. https://doi.org/10.1186/s13030-016-0059-3

Karukivi, M., Tolvanen, M., Karlsson, H., \& Karlsson, L. (2015). Alexithymia and postpartum anxiety and depression symptoms: a follow-up study in a pregnancy cohort. Journal Psychosom Obstet Gynaecol, 36(4), 142-147.

Kleiger, J. H., \& Kinsman, R. A. (1980). The development of an MMPI alexithymia scale. Psychotherapy and Psychosomatics, 34(1), 17-24. https://doi.org/10.1159/000287442

Kollenbaum, V.-E. (1994). A clinical method for the assessment of interoception of cardiovascular strain in CHD patients. Journal of Psychophysiology, 8(2), 121-130.

Kooiman, C. G., Spinhoven, P., \& Trijsburg, R. W. (2002). The assessment of alexithymia: A critical review of the literature and a psychometric study of the Toronto Alexithymia Scale20. Journal of Psychosomatic Research, 53(6), 1083-1090. https://doi.org/10.1016/S00223999(02)00348-3

Lane, R. D., \& Schwartz, G. E. (1987). Levels of emotional awareness: a cognitivedevelopmental theory and its application to psychopathology [published erratum appears in Am J Psychiatry 1987 Apr;144(4):542]. American Journal of Psychiatry, 144(2), 133-143. https://doi.org/10.1176/ajp.144.2.133

Lane, R. D., Weihs, K. L., Herring, A., Hishaw, A., \& Smith, R. (2015). Affective agnosia: Expansion of the alexithymia construct and a new opportunity to integrate and extend Freud's legacy. Neuroscience \& Biobehavioral Reviews, 55, 594-611. https://doi.org/10.1016/j.neubiorev.2015.06.007

Lépine, J. P., Godchau, M., \& Brun, P. (1985). Anxiety and depression in inpatients. Lancet, 2(8469-70), 1425-1426. https://doi.org/10.1016/S0140-6736(85)92589-9

Li, S., Zhang, B., Guo, Y., \& Zhang, J. (2015). The association between alexithymia as assessed by the 20-item Toronto Alexithymia Scale and depression: A meta-analysis. Psychiatry 
730

731

732

733

734

735

736

737

738

739

740

741

742

743

744

745

746

747

748

749

750

751

752

753

754

755

756

757

758

759

760

761

762

763

764

765

766

767

768

769

770

771

772

773

774

775
Research, 227(1), 1-9. https://doi.org/10.1016/j.psychres.2015.02.006

Loas, G., Corcos, M., Stephan, P., Pellet, J., Bizouard, P., Venisse, J. L., ... Jeammet, P. (2001). Factorial structure of the 20-item Toronto Alexithymia Scale: confirmatory factorial analyses in nonclinical and clinical samples. Journal of Psychosomatic Research, 50(5), 255-261. https://doi.org/10.1016/S0022-3999(01)00197-0

Loas, G., Otmani, O., Verrier, A., Fremaux, D., \& Marchand, M. P. (1996). Factor analysis of the French version of the 20-Item Toronto Alexithymia Scale (TAS-20). Psychopathology, 29(2), 139-144. https://doi.org/10.1159/000284983

Loas, G., Parker, J. D., Otmani, O., Verrier, A., \& Fremaux, D. (1997). Confirmatory factor analysis of the French translation of the 20-item Toronto Alexithymia Scale. Perceptual and Motor Skills, 85(3), 1018. https://doi.org/10.2466/pms.1997.85.3.1018

Luminet, O., \& Zamariola, G. (2018). Emotion knowledge and emotion regulation in alexithymia. In O. Luminet, R. M. Bagby, \& G. J. Taylor (Eds.), Alexithymia: Advances in Research, Theory, and Clinical Practice (pp. 49-77). Cambridge, United Kingdom: Cambridge University Press. https://doi.org/10.1017/9781108241595

Lumley, M. A., Neely, L. C., \& Burger, A. J. (2007). The assessment of alexithymia in medical settings: Implications for understanding and treating health problems. J Pers Assess, 89(3), 230-246. https://doi.org/10.1080/00223890701629698

MacLean, P. D. (1949). Psychosomatic disease and the visceral brain; recent developments bearing on the Papez theory of emotion. Psychosomatic Medicine, 11(6), 338-353.

Retrieved from http://www.ncbi.nlm.nih.gov/pubmed/15410445

Marty, P., \& De M’Uzan, M. (1963). La pensée opératoire. Revue Française de Psychanalyse, 27, 345-356. Retrieved from http://gallica.bnf.fr/ark:/12148/bpt6k5445905s.image.f347.langFR

Montgomery, C., Demers, S., \& Morin, Y. (2010). Le stress, les stratégies d'adaptation et l'épuisement professionnel chez les stagiaires francophones en enseignement primaire et secondaire [Stress, coping strategies, and burnout among French-speaking trainees in primary and secondary education]. Revue Canadienne de l'éducation, 33(4), 761-802. Retrieved from http://www.csse-scee.ca/CJE/Articles/FullText/CJE33-4/CJE33-4Montgomery.pdf

Müller, J., Bühner, M., \& Ellgring, H. (2003). Is there a reliable factorial structure in the 20-item Toronto Alexithymia Scale? Journal of Psychosomatic Research, 55(6), 561-568. https://doi.org/10.1016/S0022-3999(03)00033-3

Muller, L., \& Spitz, E. (2003). Évaluation multidimensionnelle du coping : validation du Brief COPE sur une population française [Multidimensional assessment of coping: validation of the Brief COPE among French population]. L'Encephale, 29(6), 507-518. Retrieved from http://www.ncbi.nlm.nih.gov/pubmed/15029085

Murphy, J., Brewer, R., Catmur, C., \& Bird, G. (2017). Interoception and psychopathology: A developmental neuroscience perspective. Developmental Cognitive Neuroscience, 23, 4556. https://doi.org/10.1016/j.dcn.2016.12.006

Murphy, J., Catmur, C., \& Bird, G. (2018). Alexithymia is associated with a multidomain, multidimensional failure of interoception: Evidence from novel tests. Journal of Experimental Psychology: General, 147(3), 398-408. https://doi.org/10.1037/xge0000366

Nemiah, J. C., \& Sifneos, P. E. (1970). Psychosomatic illness: a problem in communication. Psychotherapy and Psychosomatics, 18(1), 154-160. Retrieved from http://www.ncbi.nlm.nih.gov/pubmed/5520658

Peer) reviewing PDF | (2019:03:36066:1:1:NEW 20 Jul 2019) 
776

777

778

779

780

781

782

783

784

785

786

787

788

789

790

791

792

793

794

795

796

797

798

799

800

801

802

803

804

805

806

807

808

809

810

811

812

813

814

815

816

817

818

819

820

821
Parker, J. D. A., Bagby, R. M., Taylor, G. J., Endler, N. S., \& Schmitz, P. (1993). Factorial validity of the 20-item Toronto Alexithymia Scale. European Journal of Personality, 7(4), 221-232. https://doi.org/10.1002/per.2410070403

Plaisant, O., Courtois, R., Réveillère, C., Mendelsohn, G. A., \& John, O. P. (2010). Validation par analyse factorielle du Big Five Inventory français (BFI-Fr). Analyse convergente avec le NEO-PI-R [Factorial validation of the French Big Five Inventory (BFI-Fr). Convergent analysis with NEO-PI-R]. Annales Medico-Psychologiques, 168(2), 97-106. https://doi.org/10.1016/j.amp.2009.09.003

Pollatos, O., \& Herbert, B. M. (2018). Interoception: Definitions, dimensions, neural substrates. In G. Hauke \& A. Kritikos (Eds.), Embodiment in Psychotherapy. A Practitioner's Guide (pp. 15-27). Basel, Switzerland: Springer International Publishing. https://doi.org/10.1007/978-3-319-92889-0_2

Porcelli, P., \& Taylor, G. J. (2018). Alexithymia and physical illness: A psychosomatic approach. In O. Luminet, R. M. Bagby, \& G. J. Taylor (Eds.), Alexithymia: Advances in Research, Theory, and Clinical Practice (pp. 105-126). New York: Cambridge University Press. https://doi.org/10.1017/9781108241595

Ring, C., Brener, J., Knapp, K., \& Mailloux, J. (2015). Effects of heartbeat feedback on beliefs about heart rate and heartbeat counting: A cautionary tale about interoceptive awareness. Biological Psychology, 104, 193-198. https://doi.org/10.1016/j.biopsycho.2014.12.010

Ruesch, J. (1948). The infantile personality. The core problem of psychosomatic medicine. Psychosomatic Medicine, 10(3), 134-144. Retrieved from http://www.ncbi.nlm.nih.gov/pubmed/18872182

Schandry, R. (1981). Heart beat perception and emotional experience. Psychophysiology, 18(4), 483-488.

Sekely, A., Bagby, R. M., \& Porcelli, P. (2018). Alexithymia: Advances in Research, Theory, and Clinical Practice. In O. Luminet, R. M. Bagby, \& G. J. Taylor (Eds.), Alexithymia: Advances in Research, Theory, and Clinical Practice (pp. 17-32). Cambridge, United Kingdom: Cambridge University Press. https://doi.org/10.1017/9781108241595

Shah, P., Hall, R., Catmur, C., \& Bird, G. (2016). Alexithymia, not autisme, is associated with impaired interoception. Cortex, 81, 215-220. https://doi.org/10.1016/j.cortex.2016.03.021

Sifneos, P. E. (1973). The prevalence of 'alexithymic' characteristics in psychosomatic patients. Psychotherapy and Psychosomatics, 22(2), 255-262. https://doi.org/10.1159/000286529

Silva, H., Freitas, J., Moreira, S., Santos, A., \& Almeida, V. (2016). Alexithymia and psychopathology in patients with acute myocardial infarction. Acta Cardiologica, 71(2), 213-220. https://doi.org/10.1080/AC.71.2.3141852

Spielberger, C. D., Gorsuch, R. L., Lushene, R., Vagg, P. R., \& Jacobs, G. A. (1983). Manual for the State-Trait Anxiety Inventory STAI-Form Y. Palo Alto, CA: Consulting Psychologists Press. Retrieved from http://www.apa.org/pi/about/publications/caregivers/practicesettings/assessment/tools/trait-state.aspx

Taber, K. S. (2017). The Use of Cronbach's Alpha When Developing and Reporting Research Instruments in Science Education. Research in Science Education. https://doi.org/10.1007/s11165-016-9602-2

Taylor, G. J., \& Bagby, R. M. (2013). Psychoanalysis and Empirical Research. Journal of the American Psychoanalytic Association, 61(1), 99-133.

https://doi.org/10.1177/0003065112474066

Taylor, G. J., Bagby, R. M., \& Parker, J. D. (1992). The Revised Toronto Alexithymia Scale: 
822

823

824

825

826

827

828

829

830

831

832

833

834

835

836

837

838

839

840

841

842

843

844

845

846

847

848

849

850

851

852

853

854

855

856

some reliability, validity, and normative data. Psychotherapy and Psychosomatics, 57(1-2), 34-41. Retrieved from http://www.ncbi.nlm.nih.gov/pubmed/1584897

Taylor, G. J., Bagby, R. M., \& Parker, J. D. A. (2003). The 20-Item Toronto Alexithymia Scale IV. Reliability and factorial validity in different languages and cultures. Journal of Psychosomatic Research, 55(3), 277-283. https://doi.org/10.1016/S0022-3999(02)00601-3

Taylor, G. J., Ryan, D., \& Bagby, R. M. (1985). Toward the development of a new self-report alexithymia scale. Psychotherapy and Psychosomatics, 44(4), 191-199. Retrieved from http://www.ncbi.nlm.nih.gov/pubmed/3837277

Thoma, N. C., \& Greenberg, L. S. (2015). Integrating emotion-focused therapy into cognitivebehavioral therapy. In N. C. Thoma \& D. McKay (Eds.), Working with emotion in cognitive-behavioral therapy: Techniques for clinical practice (pp. 239-262). New York: The Guilford Press.

Tolmunen, T., Lehto, S. M., Heliste, M., Kurl, S., \& Kauhanen, J. (2010). Alexithymia Is Associated With Increased Cardiovascular Mortality in Middle-Aged Finnish Men. Psychosomatic Medicine, 72(2), 187-191. https://doi.org/10.1097/PSY.0b013e3181c65d00

Tominaga, T., Choi, H., Nagoshi, Y., Wada, Y., \& Fukui, K. (2014). Relationship between alexithymia and coping strategies in patients with somatoform disorder. Neuropsychiatric Disease and Treatment, 10, 55-62. https://doi.org/10.2147/NDT.S55956

Weiss, A., \& Costa, P. T. (2005). Domain and Facet Personality Predictors of All-Cause Mortality Among Medicare Patients Aged 65 to 100. Psychosomatic Medicine, 67(5), 724 733. https://doi.org/10.1097/01.psy.0000181272.58103.18

Zamariola, G., Frost, N., Van Oost, A., Corneille, O., \& Luminet, O. (2019). Relationship between interoception and emotion regulation: New evidence from mixed methods. Journal of Affective Disorders, 246, 480-485. https://doi.org/10.1016/j.jad.2018.12.101

Zamariola, G., Vlemincx, E., Corneille, O., \& Luminet, O. (2018). Relationship between interoceptive accuracy, interoceptive sensibility, and alexithymia. Personality and Individual Differences, 125, 14-20. https://doi.org/10.1016/j.paid.2017.12.024

Zhu, X., Yi, J., Yao, S., Ryder, A. G., Taylor, G. J., \& Bagby, R. M. (2007). Cross-cultural validation of a Chinese translation of the 20-item Toronto Alexithymia Scale. Comprehensive Psychiatry, 48(5), 489-496. https://doi.org/10.1016/j.comppsych.2007.04.007

Zigmond, A. S., \& Snaith, R. P. (1983). The Hospital Anxiety and Depression Scale. Acta Psychiatrica Scandinavica, 67(6), 361-370. https://doi.org/10.1111/j.16000447.1983.tb09716.x 


\section{Table $\mathbf{1}$ (on next page)}

Socio-demographic, general health, and psychological data for both samples

Notes. ${ }^{* *} p<.01,{ }^{* * *} p<.001$. Data represents means \pm SD. ${ }^{a}$ regards differences between Study 1 and Study 2; ANOVA Test or Chi2-Test. To compare the samples, alexithymia scores from Study 1 were transformed into a 5-point Likert scale. ${ }^{1}$ The "others" category included drugs with a low frequency of use such as beta-blocker or immunosuppressant. The detailed list of medications may include multiple intakes. The same participant could be included in two categories of drugs. 


\begin{tabular}{|c|c|c|c|}
\hline & $\begin{array}{c}\text { Total sample } \\
\text { STUDY } 1\end{array}$ & $\begin{array}{c}\text { Total sample } \\
\text { STUDY } 2\end{array}$ & $p$-value ${ }^{a}$ \\
\hline \multicolumn{4}{|l|}{ Socio-demographic data } \\
\hline Number of participants & 253 & 287 & \\
\hline Percentage of Women & $69.57 \%$ & $87.8 \%$ & $<.001^{* * *}$ \\
\hline Age & $29.65 \pm 13.82$ & $19.56 \pm 1.58$ & $<.001^{* * *}$ \\
\hline \multicolumn{4}{|l|}{ Health data } \\
\hline Cardiovascular disease, $\mathrm{n}$ (\% of sample) & $13(5.14)$ & $13(4.53)$ & .841 \\
\hline Eating disorders, $\mathrm{n}$ (\% of sample) & $24(9.49)$ & $22(7.66)$ & .537 \\
\hline Somatic disorders, $\mathrm{n}$ ( $\%$ of sample) & $11(4.35)$ & $13(4.53)$ & 1 \\
\hline Medication intake, $n$ ( $\%$ of sample) & $32(12.65)$ & $34(11.85)$ & .42 \\
\hline Anxiolytics & 3 & 5 & \\
\hline Antidepressants & 6 & 4 & \\
\hline Anti-inflammatory drugs & 2 & 1 & \\
\hline Antihistamines & 2 & 5 & \\
\hline Migraine medications & 1 & 4 & \\
\hline Asthma medications & 4 & 1 & \\
\hline Others $^{1}$ & 19 & 16 & \\
\hline
\end{tabular}

\section{Psychological data}

\begin{tabular}{rccc}
\hline TAS-20 (/ 100) & $48.58 \pm 10.87$ & $51.59 \pm 11.62$ & $.002^{* *}$ \\
DIF (/ 35) & $15.09 \pm 5.02$ & $18.79 \pm 6.33$ & $<.001^{* * *}$ \\
DDF (/ 25) & $13.41 \pm 4.53$ & $15.19 \pm 4.70$ & $<.001^{* * *}$ \\
EOT (/ 40) & $20.08 \pm 4.70$ & $17.61 \pm 4.15$ & $<.001^{* * *}$ \\
\hline STAI-T (/ 80) & $42.14 \pm 9.66$ & $45.53 \pm 9.71$ & $<.001^{* * *}$ \\
HADS-D (/21) & $3.71 \pm 2.90$ & - & \\
BDI-13 (/ 39) & - & $18.85 \pm 4.56$ & \\
BFI-N (/ 40) & $21.02 \pm 6.94$ & $23.62 \pm 6.80$ & $<.001^{* * *}$ \\
PSS (/ 40) & $26.74 \pm 7.48$ & $29.40 \pm 7.47$ & $<.001^{* * *}$ \\
\hline Brief Cope & & &
\end{tabular}




\begin{tabular}{llrr}
\hline Functional coping $(/ 8)$ & $5.20 \pm 1.30$ & $5.14 \pm 1.10$ & .535 \\
Coping with varying functionality (/ 8) & $4.43 \pm 1.02$ & $4.52 \pm 0.92$ & .105 \\
Dysfunctional coping $(/ 8)$ & $3.03 \pm 0.86$ & $3.22 \pm 0.83$ & $.008^{* *}$ \\
\hline
\end{tabular}

2 


\section{Table 2 (on next page)}

Loadings after Oblimin rotation from the EFA of the TAS-20, from the EFA of the TAS without items 16 and 20, and comparative attribution of items in Study 1.

Notes. Factor loadings are highlighted in bold type. For easy reading, all values of loading $<.30$ were not reported, except if they explained the factor. 


\begin{tabular}{|c|c|c|c|c|c|c|c|c|c|c|c|}
\hline \multirow[t]{2}{*}{ Items } & \multicolumn{5}{|c|}{ Factor (F) } & \multicolumn{4}{|c|}{ Latent Factor (LF) } & \multirow{2}{*}{$\begin{array}{l}\text { Theoretical } \\
\text { attribution }\end{array}$} & \multirow{2}{*}{$\begin{array}{c}\text { New } \\
\text { attribution }\end{array}$} \\
\hline & F1 & F2 & F3 & F4 & F5 & LF1 & LF2 & LF3 & LF4 & & \\
\hline 1 & .75 & & & & & .76 & & & & DIF & LF1 \\
\hline 2 & .58 & & & & .41 & .60 & & & .37 & DDF & LF1 \\
\hline 3 & & & .57 & & & & & .57 & & DIF & LF3 \\
\hline 4 & & & & & .45 & .38 & & & .44 & DDF & LF4 \\
\hline 5 & & .29 & & & & & .38 & & & EOT & LF2 \\
\hline 6 & .59 & & & & & .58 & & & & DIF & LF1 \\
\hline 7 & & & .74 & & & & & .77 & & DIF & LF3 \\
\hline 8 & & .24 & & & & & .33 & & & EOT & LF2 \\
\hline 9 & .75 & & & & & .74 & & & & DIF & LF1 \\
\hline 10 & & .61 & & & & & .59 & & & EOT & LF2 \\
\hline 11 & .51 & & & & & .53 & & & & DDF & LF1 \\
\hline 12 & & & & & .50 & .30 & & & .47 & DDF & LF4 \\
\hline 13 & .69 & & & & & .72 & & & & DIF & LF1 \\
\hline 14 & .47 & & & & & .45 & & & & DIF & LF1 \\
\hline 15 & & .35 & & & .41 & & .37 & & .41 & EOT & LF4 \\
\hline 16 & & & & .41 & & - & - & - & - & EOT & - \\
\hline 17 & & & & & .61 & & & & .65 & DDF & LF4 \\
\hline 18 & & .35 & & & & & .37 & & & EOT & LF2 \\
\hline 19 & & .71 & & & & & .73 & & & EOT & LF2 \\
\hline
\end{tabular}




\begin{tabular}{ccccccccccc}
20 & & & & $\mathbf{. 6 8}$ & & - & - & - & - & EOT \\
\hline Eigenvalues & 5.49 & 2.15 & 1.55 & 1.20 & 1.12 & 5.47 & 2.06 & 1.47 & 1.09 & \\
\% of variance & 27.44 & 10.76 & 7.74 & 5.98 & 5.61 & 30.37 & 11.43 & 8.17 & 6.04 & \\
$\quad \boldsymbol{\alpha}$ & .85 & .62 & .66 & .36 & .68 & .85 & .62 & .66 & .68 & \\
\hline
\end{tabular}




\section{Table 3 (on next page)}

Loadings after Oblimin rotation from the EFA of the TAS without items 16 and 20, and comparative attribution of items in Study 2.

Notes. Factor loadings are highlighted in bold type. For easy reading, all values of loading $<.30$ were not reported, except if they explained the factor. 


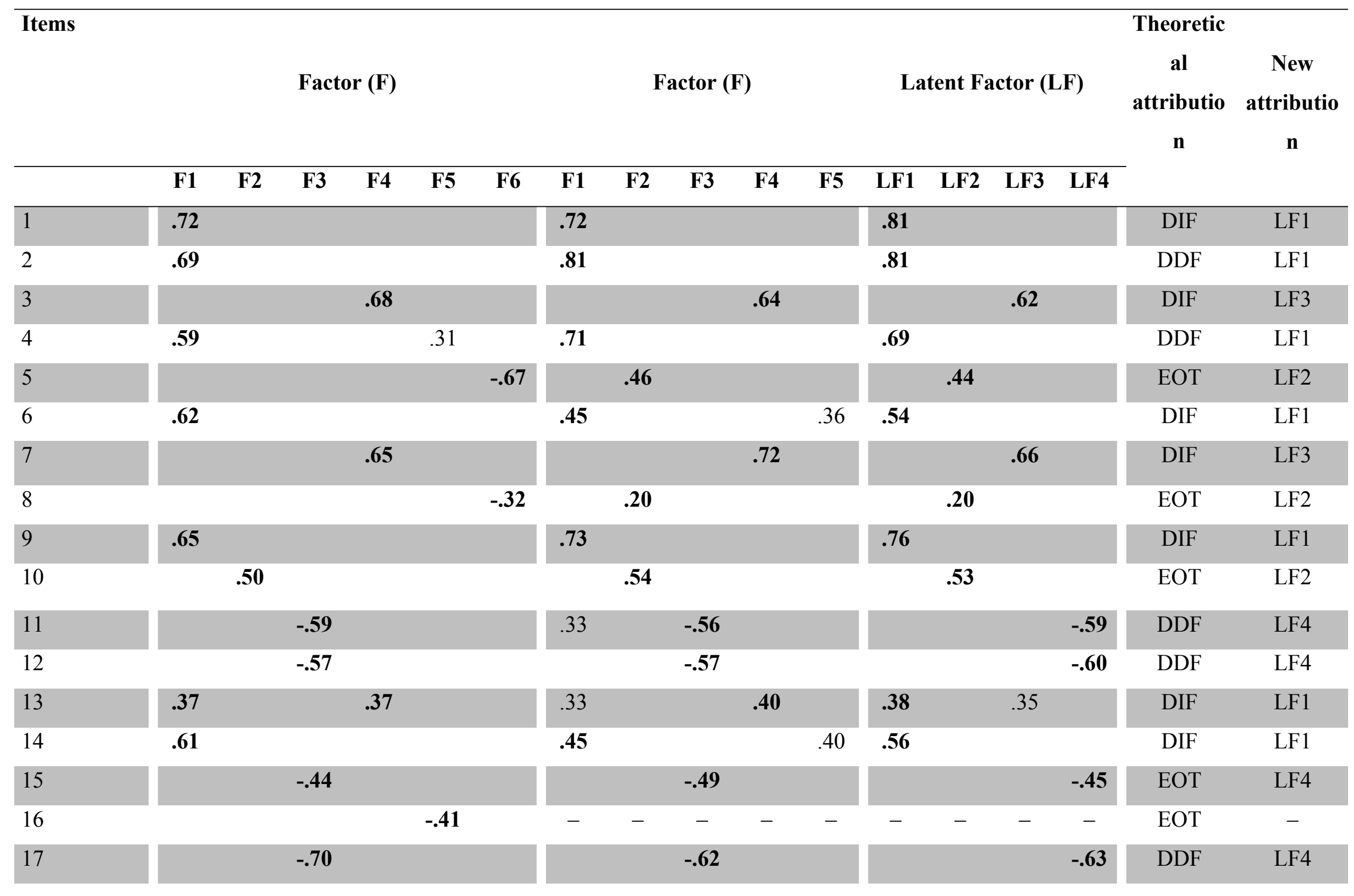




\begin{tabular}{|c|c|c|c|c|c|c|c|c|c|c|c|c|c|c|c|c|c|}
\hline 18 & & .40 & & & & & & .43 & & & & & .44 & & & EOT & LF2 \\
\hline 19 & & .62 & & & & & & .54 & & & & & .55 & & & EOT & LF2 \\
\hline 20 & & & & & -.40 & & - & - & - & - & - & - & - & - & - & EOT & - \\
\hline Eigenvalues & 5.57 & 2.07 & 1.49 & 1.20 & 1.12 & 1.07 & 5.51 & 1.87 & 1.47 & 1.10 & 1.02 & 5.51 & 1.87 & 1.10 & 1.47 & & \\
\hline$\%$ of & 27.8 & 10.3 & & & & & 30.6 & 10.3 & 8.14 & 6.13 & 5.67 & 30.6 & 10.3 & 6.13 & 8.14 & & \\
\hline variance & 5 & 6 & 7.43 & 6.00 & 5.59 & 5.34 & 1 & 9 & & & & 1 & 9 & & & & \\
\hline$\alpha$ & .88 & .51 & .70 & .71 & .43 & .37 & .86 & .51 & .70 & .71 & - & .88 & .51 & .64 & .70 & & \\
\hline
\end{tabular}


Table 4 (on next page)

Detailed results of the multivariate logistic regression analyses

Notes. ${ }^{t} p<.07, * p<.05,{ }^{* *} p<.01,{ }^{* * *} p<.001$. 


\begin{tabular}{|c|c|c|c|c|c|c|c|c|c|}
\hline & & \multicolumn{4}{|c|}{ STUDY 1} & \multicolumn{4}{|c|}{ STUDY 2} \\
\hline & & $\begin{array}{l}\text { Somatic } \\
\text { disorders }\end{array}$ & $\begin{array}{l}\text { Eating } \\
\text { disorders }\end{array}$ & $\begin{array}{l}\text { Medication } \\
\text { intake }\end{array}$ & $\begin{array}{l}\text { Cardiovascular } \\
\text { diseases }\end{array}$ & $\begin{array}{l}\text { Somatic } \\
\text { disorders }\end{array}$ & $\begin{array}{l}\text { Eating } \\
\text { disorders }\end{array}$ & $\begin{array}{l}\text { Medication } \\
\text { intake }\end{array}$ & $\begin{array}{l}\text { Cardiovascular } \\
\text { diseases }\end{array}$ \\
\hline \multirow{4}{*}{$\begin{array}{l}\text { Latent } \\
\text { Factor } \\
1 \text { (LF1) }\end{array}$} & $B$ & -0.10 & 0.13 & -0.01 & 0.07 & -0.07 & -0.06 & 0.04 & 0.06 \\
\hline & Wald & 1.19 & 5.64 & 0.05 & 0.78 & 1.01 & 1.53 & 1.1 & 0.89 \\
\hline & $\operatorname{Exp}(B)$ & 0.9 & 1.14 & 1.01 & 1.07 & 0.94 & 0.94 & 1.04 & 1.06 \\
\hline & $p$ & .276 & $.018^{*}$ & .820 & .376 & .315 & .216 & .294 & .346 \\
\hline \multirow{4}{*}{$\begin{array}{l}\text { Latent } \\
\text { Factor } \\
2 \text { (LF2) }\end{array}$} & $B$ & -0.06 & -0.05 & -0.01 & -0.14 & -0.06 & -0.03 & -0.07 & 0.08 \\
\hline & Wald & 0.23 & 0.32 & 0.01 & 1.46 & 0.28 & 0.121 & 1.05 & 0.56 \\
\hline & $\operatorname{Exp}(B)$ & 0.94 & 0.95 & 0.99 & 0.87 & 0.94 & 0.97 & 0.93 & 1.08 \\
\hline & $p$ & .632 & .570 & .934 & .227 & .597 & .728 & .305 & .454 \\
\hline \multirow{4}{*}{$\begin{array}{l}\text { Latent } \\
\text { Factor } \\
3 \text { (LF3) }\end{array}$} & $B$ & 0.62 & 0.14 & 0.39 & 0.17 & 0.74 & 0.33 & 0.22 & 0.34 \\
\hline & Wald & 11.40 & 0.86 & 9.06 & 0.75 & 15.68 & 8.72 & 5.40 & 5.22 \\
\hline & $\operatorname{Exp}(B)$ & 1.86 & 1.15 & 1.47 & 1.18 & 2.09 & 1.40 & 1.25 & 1.41 \\
\hline & $p$ & $.001^{* * *}$ & .354 & $.003^{* *}$ & .387 & $<.001^{* * *}$ & $.003^{* *}$ & $.020^{*}$ & $.022^{*}$ \\
\hline \multirow{4}{*}{$\begin{array}{l}\text { Latent } \\
\text { Factor } \\
4 \text { (LF4) }\end{array}$} & $B$ & 0.01 & -0.03 & -0.17 & -0.001 & -0.13 & 0.01 & -0.12 & -0.10 \\
\hline & Wald & 0.004 & 0.08 & 3.87 & 0.00 & 1.45 & 0.01 & 3.38 & 1.05 \\
\hline & $\operatorname{Exp}(B)$ & 1.01 & 0.97 & 0.84 & 1 & 0.88 & 1.01 & 0.89 & 0.9 \\
\hline & $p$ & .951 & .781 & $.049^{*}$ & .995 & .228 & .941 & $.066^{\mathrm{t}}$ & .306 \\
\hline
\end{tabular}




\section{Table 5 (on next page)}

Detailed results of the multivariate regression analyses

Notes. ${ }^{\mathrm{t}} \mathrm{p}<.07, * \mathrm{p}<.05, * * \mathrm{p}<.01,{ }^{* * *} \mathrm{p}<.001$. STAI-T=State-Trait Anxiety Inventory, HADS-D=Depression subscale of the Hospital Anxiety and Depression Scale, BDI-13=Beck Depression Inventory-13, BFI-N=Neuroticism dimension of the Big Five Inventory, PSS=Perceived Stress Scale, F-D=Difference score between functional and dysfunctional coping from Brief Cope. 


\begin{tabular}{llllllllllll}
\hline & & \multicolumn{1}{c}{ STUDY 1 } & & \multicolumn{4}{c}{ STUDY 2 } \\
\hline & & STAI-T & HADS-D & BFI-N & PSS & F-D & STAI-T & BDI-13 & BFI-N & PSS & F-D \\
\hline & $\boldsymbol{B}$ & 1.17 & 0.22 & 0.72 & 0.73 & -0.09 & 0.67 & 0.23 & 0.42 & 0.45 & -0.10 \\
Latent factor 1 (LF1) & $\mathbf{t}$ & 8.13 & 4.74 & 6.40 & 6.17 & -3.36 & 7.04 & 4.88 & 5.87 & 5.81 & -6.00 \\
& $\boldsymbol{p}$ & $<.001^{* * *}$ & $<.001^{* * *}$ & $<.001^{* * *}$ & $<.001^{* * *}$ & $.001^{* * *}$ & $<.001^{* * *}$ & $<.001^{* * *}$ & $<.001^{* * *}$ & $<.001^{* * *}$ & $<.001^{* * *}$ \\
\hline & $\boldsymbol{B}$ & 0.32 & 0.21 & 0.07 & 0.19 & -0.23 & -0.14 & -0.06 & -0.04 & -0.03 & -0.06 \\
Latent factor 2 (LF2) & $\mathbf{t}$ & 1.56 & 3.23 & 0.46 & 1.13 & -5.71 & -0.79 & -0.64 & -0.32 & -0.21 & -1.95 \\
& $\boldsymbol{p}$ & .120 & $.001^{* * *}$ & .646 & .261 & $<.001^{* * *}$ & .433 & .523 & .750 & .833 & $.053^{\mathrm{t}}$ \\
\hline & $\boldsymbol{B}$ & 0.67 & 0.31 & 0.56 & 0.65 & -0.15 & 0.98 & 0.40 & 0.67 & 0.57 & -0.10 \\
Latent factor 3 (LF3) & $\mathbf{t}$ & 1.72 & 2.53 & 1.83 & 2.02 & -1.93 & 3.96 & 3.21 & 3.66 & 2.84 & -2.42 \\
& $\boldsymbol{p}$ & .088 & $.012^{*}$ & $.068^{\mathrm{t}}$ & $.045^{*}$ & $.054^{\mathrm{t}}$ & $<.001^{* * *}$ & $.001^{* * *}$ & $<.001^{* * *}$ & $.005^{* *}$ & $.016^{*}$ \\
\hline & $\boldsymbol{B}$ & -0.20 & 0.03 & -0.36 & -0.03 & 0.01 & -0.16 & 0.06 & -0.26 & 0.02 & 0.03 \\
Latent factor 4 (LF4) & $\mathbf{t}$ & -0.94 & 0.50 & -2.15 & -0.20 & 0.17 & -1.06 & 0.75 & -2.34 & 0.19 & 1.30 \\
& $\boldsymbol{p}$ & .346 & .618 & $.033^{*}$ & .844 & .868 & .290 & .451 & $.020^{*}$ & .846 & .195 \\
\hline
\end{tabular}




\section{Table 6(on next page)}

Associations between the latent factors and psychological and physical health measures

Notes. ${ }^{\mathrm{t}} \mathrm{p}<.07, * \mathrm{p}<.05,{ }^{* *} \mathrm{p}<.01,{ }^{* * *} \mathrm{p}<.001 . \mathrm{B}^{1}$ are the results of the analyses of the Study 1 and $B^{2}$ are the results of the analyses of the Study 2 . 


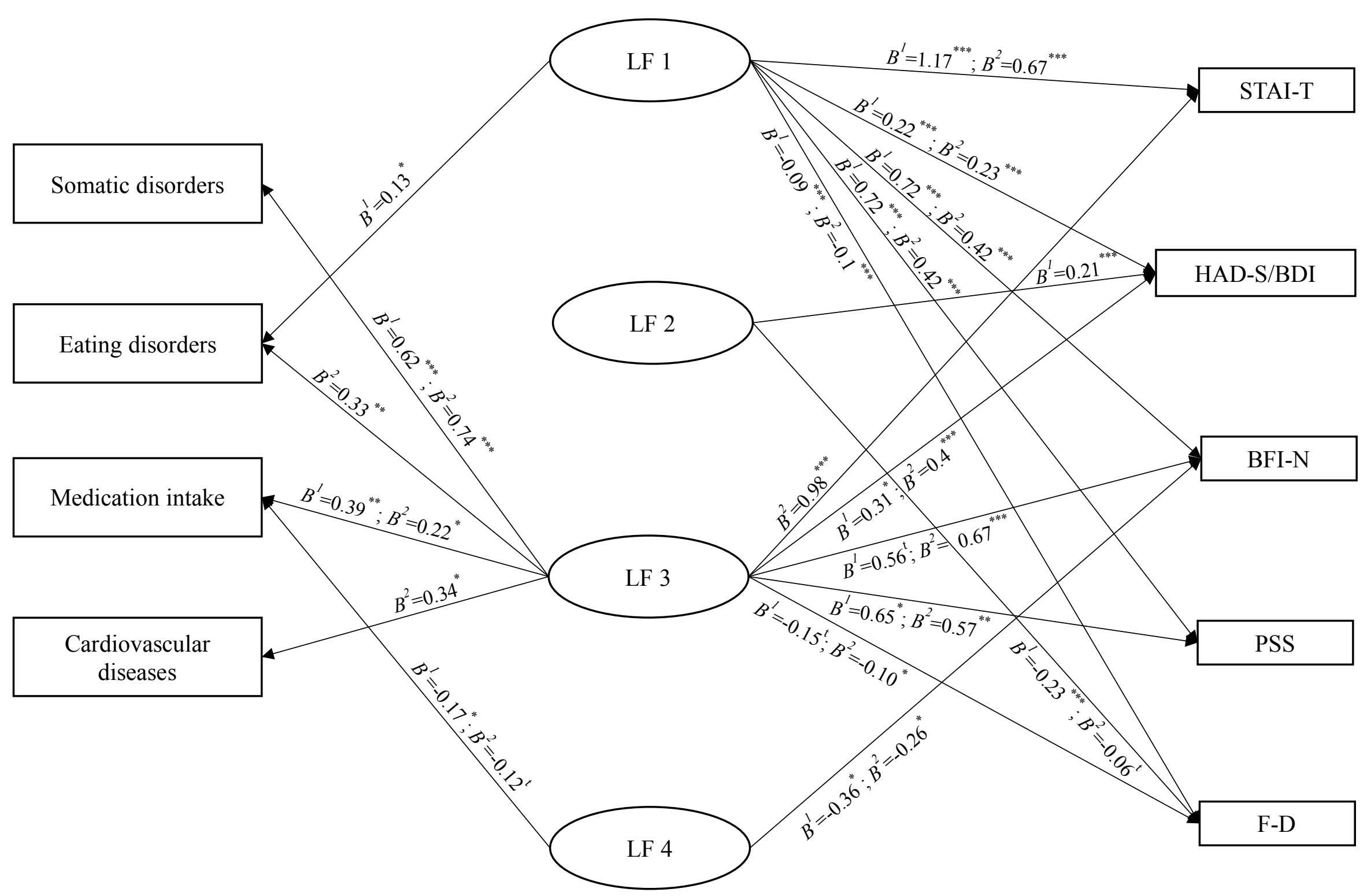

